\title{
THE DEVELOPMENT OF LIFE-LONG LEARNING COMPETENCIES: POSITIONING STUDENTS FOR SELF-REGULATION
}

\author{
Richard J. Aleong, Research Associate and \\ David S. Strong, Professor \& NSERC Chair in Design Engineering \\ Faculty of Engineering and Applied Science, Queen's University, Kingston, Ontario, Canada \\ r.aleong@queensu.ca, strongd@queensu.ca
}

\begin{abstract}
Within the engineering attribute of life-long learning is the ability for self-regulation, described as the process in which students plan, monitor, control, and adjust their behaviour to meet specific goals. To be selfregulating requires a degree of self-awareness and selfreflection to build knowledge about the self. This selfknowledge contributes to one's values, personal identity, and motivational beliefs that may direct academic behaviour. In this paper, we present insight into the implementation of a workshop program designed to engage undergraduate engineering students in a facilitated self-reflective process. The workshop program challenged participants to think about how they see themselves in their engineering education and how they envision the person they wish to become in their future career. The research aims to offer educators with pedagogical insight into students' sense of self, selfregulating processes, and new ways to promote the skills of life-long learning.
\end{abstract}

Keywords: life-long learning, self-regulation, selfreflection, self-efficacy, personal development, engineering education

\section{INTRODUCTION}

With engineering accreditation boards around the globe recognizing life-long learning as an attribute of graduating engineers, engineering educators are called upon to create innovative pedagogy to advance life-long learning skills development and assessment. Central to the competency of life-long learning is the ability for students to be self-regulating, described as the process in which students plan, monitor, control, and adjust their behaviour to meet specific goals. Inherent in the self-regulating process is the practice of reflection to make meaning from one's experiences and to formulate new plans for moving forward [1]. Recognizing the increasing need for reflection, new initiatives and collaborations that support the promotion of reflection in engineering education have recently been established [2].
Current literature discusses the promotion of life-long learning skills and reflection in the academic contextthat is, the development of life-long learning competencies through learning tasks associated with specific academic courses. For example, Wertz, Purzer, Fosmire, and Cardella [3] explored information literacy skills through team memos of first year engineering students in an introductory design course. Pomales-García and Barreto [4] conducted a comparative analysis of students' self-reflections on their experiences with project-based learning within an engineering design course.

Beyond the academic context, our work aims to extend the promotion of life-long learning skills through selfreflection in the context of students' personal and professional development. This approach is aligned with a humanistic curriculum [5] orientation that focuses on personal development in one's curriculum through intrinsically rewarding experiences.

In our research, we have utilized the process of selfreflection as a means for students to explore and generate their thoughts about how they see themselves in their engineering education and how they envision the person they wish to become in their future career. This type of self-reflection may support the identification of one's individual learning needs, assessment methods, and motivations for life-long learning, as well as position students for goal setting, establishing of personal values and beliefs, and identifying self-regulating strategies.

Our goal is to position students for self-regulation by providing them with the opportunities to engage in selfreflection, aimed at self-discovery, and to share experiences with their peers. To this end, we invited undergraduate engineering students to participate in a two-part workshop series of self-reflective and peer discussion exercises. The workshop program provided students with a value-added learning opportunity outside of the traditional engineering curriculum to support their development of life-long learning skills. As well, the workshops served as our research method for data collection of participants' reflections. 
In this paper, we present an overview of our research methods along with insight that emerged from our findings to offer implications in support of future selfreflection research and pedagogy. We explore how educators can foster students' self-reflection, in the classroom and across the curriculum, directed towards students' personal and professional development.

\section{METHODS}

In this section, we describe the workshop program to engage students in self-reflection and the accompanying data collection and analysis methods.

\subsection{Workshop Design}

The workshop program consisted of a series of two facilitated workshops (each two hours in duration) and was offered as a voluntary professional development opportunity to all undergraduate engineering students at one mid-size university. The workshop exercises aimed to engage students in reflection about their past experiences, their current learning, and their future expectations for their career. Participants were also asked to write a personal statement outside of the workshop sessions that discussed how they see themselves in their current studies and how they envision the person they wish to become in their future engineering career. Although we have previously reported on the design and the theoretical framework used for the workshop program [6], we present the following overall workshop objectives to set the context for this paper. Through an exploratory selfreflective process, the workshops aimed to:

1. Engage students in reflective thinking about their past experiences, their current position in engineering education, and their future in engineering professional practice

2. Support students in articulating how they position themselves for their engineering studies and future careers through a written personal statement

3. Foster in students a sense of life-long learning with the skills of reflection and self-directedness

In this way, students may be supported in selfdiscovery directed towards their personal and professional development.

\subsection{Data Collection}

Participants' responses in the workshops and personal statements were collected using a web-based platform. Four undergraduate engineering students completed the full workshop program. Two male students (Andrew and
John) were in their second year and two female students (Sarah and Michelle) were in their final year after completing a 16-month professional internship. Pseudonyms have been used to protect participant confidentiality.

\subsection{Data Analysis}

A preliminary analysis of the research data was conducted consisting of an exploratory review of the data to deconstruct participants' responses to the basic units of understanding [7]. Responses from participants' individual reflections and from their personal statements were deconstructed through a coding process that involved assigning key words and phrases as identifiers of participants' thoughts and ideas. Written annotations were also included during the process of reviewing the data that revealed further questions and areas of interest in the data. Future qualitative analysis will involve deeper interrogation with the data to compare the data across participants and to explore the contextual layers within participants' reflections.

\section{FINDINGS AND DISCUSSION}

We offer three thematic areas to consider for fostering self-reflective activities related to students' personal development in the classroom and across the curriculum: 1) identifying students' purpose and need for personal development, 2) recognizing the role and impact of selfreflection on personal development and 3) integrating personal learning with academic courses.

These themes, emerging from our research findings, highlight challenges and opportunities for future selfreflection research and pedagogy.

\subsection{Identifying Students' Purpose and Need for Personal Development}

Within this theme, we recognize the importance for students and educators to identify the purpose and need for personal development. For students, exploring one's purpose was one of the intended learning outcomes of the workshop exercises and guided their self-reflections. For educators, understanding students' purpose and needs may support research recruitment strategies.

3.1.1 Exploring Students' Purpose and Need. The process of self-reflection may be an unfamiliar and uncomfortable experience for some students. This may be due to students' lack of experience with reflective activities or the open-ended nature of self-reflection. In the workshop sessions, the reflective exercises were designed to support students in writing their statements in 
a relevant and meaningful way. Based on John's feedback, the workshops served to reaffirm his purpose and goals. For Sarah, the workshops exposed her to new ways of thinking.

To engage students in the self-reflective process, it may be beneficial for students to identify their own problem definition so that they are able to formulate a personal statement to meet their unique purposes and intentions. For example, Michelle described the purpose of her statement in her opening paragraph:

The purpose of this personal statement is to remind me of things to be aware of and what I should be doing. It has the goal of making my journey more efficient and hopefully help me discover areas of my goals that need more focus and exercises to get there. (Michelle)

To support students in identifying their own purpose and needs for personal development, the workshops offered a socially interactive learning opportunity. The workshop program allowed for peer discussion at key points throughout the reflective exercises. As well, the first part of the second workshop was dedicated to a guided peer review of participants' statements. It was desirable for participants to share and discuss their reflections and experiences, so that they may learn from their peers and construct new understanding together. During the exercises, it was a challenge to distinguish between participants' individual ideas and the thoughts that came from the peer discussion. The first researcher, in the role of workshop facilitator, encouraged students to individually reflect and record their reflections, and then share with their peers. There was also time allotted in the workshops to reflect on the peer discussion and record one's subsequent thoughts.

3.1.2 Implications for Research Recruitment Strategies. Although the workshop program was open to all undergraduate engineering students, recruitment of participants for the workshop program was a challenge. We have conceptualized students' motivation to participate along the dimensions of desire and ability (Table 1). Students' desire to participate in the workshop is represented by their interest to participate. Students' ability to participate is represented by students' beliefs in whether or not they have time to participate. The challenge was to create the conditions that would move students from Quadrants 1, 2, and 3, to Quadrant 4.
Table 1: Matrix of prospective participants' desire and ability leading to participation.

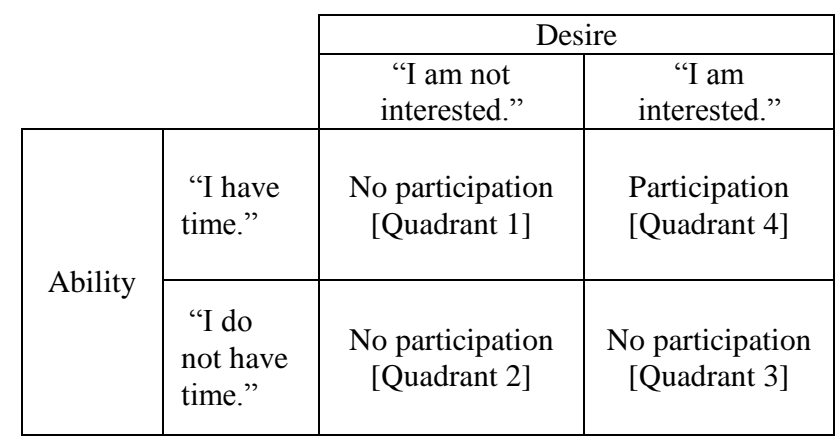

This matrix assumes that students were aware of the workshops since a direct recruitment email was distributed to all eligible participants and recruitment messages through social media were also posted. Another element for consideration is students' readiness to receive such information. Since this was a new initiative, perhaps students ignored the recruitment email as they were not looking for these opportunities, raising the question of whether or not personal and professional development activities are on the minds of students. To account for these elements, a brief information session was held the week before the workshops took place so that students could learn more about the opportunity.

While each quadrant can statically represent the extreme case of student's desire and ability, we recognize that participants' motivation is complicated and dynamic. Therefore, we interpret the factors of desire and ability to be on a scale from low to high levels (0-10), and these levels may change over time. The very bottom left-hand corner of Quadrant 2 represents a position of very low ability (level 0 ) and very low desirability (level 0 ). The upper most right hand corner of Quadrant 4 represents a position of very high ability (level 10) and very high desirability (level 10). For example, a student may have a moderate level of desire to participate upon receiving the first recruitment email, but finds that this desire decreases as other priorities arise that compete for the student's time.

Although we do not intend to present a comprehensive analysis of the many factors that may contribute to the students' motivation to participate, we have identified a number of participation factors for future consideration:

- Students' awareness of the workshop

- Students' feelings of readiness for the workshop, ie. "I don't think this is for me"

- Students' expectancy belief that the exercise will be beneficial and students' value perceptions of selfreflection

- Timing of the workshops during the semester 
- Time commitment required

- Messaging of the workshops to students

The low participation in this study raises concerns of students' attitudes and receptiveness towards personal and professional development opportunities. Exploring the relationship and characteristics between the above participation factors within the desire and ability dimensions in Table 1 may reveal insight to increase participation in future studies.

\subsection{Recognizing the Role and Impact of Self- Reflection on Personal Development}

In order to foster meaningful self-reflection among students, it is helpful to identify what self-reflection may look like when directed towards personal development within unique contexts. The context of our research was that of a voluntary professional development workshop that challenged students to self-reflect on their holistic educational experience as an engineering student. Identifying indicators of the role and impact of selfreflection may serve as launching points for educators to scaffold the construction of further learning, and for students to position themselves in relation to similar experiences.

As an example of the role of self-reflection, John found the process to be satisfying as well as providing validation for his current direction of his studies. John highlighted his purpose as being driven by continuous self-improvement in all aspects of life. He felt that the development of his personal statement made him consider what his education means to him.

It was also evident that the self-reflection activities may have different roles and outcomes for each participant, due to each individual's unique interpretation of the task. Andrew's personal statement was highly characterized by reflection on past experiences and recognition of current challenges and opportunities for his learning. In comparison, John's statement was forward thinking-outlining his goals, priorities, and personal definition of success for the future. In the peer discussion reflective response, John wrote "It's surprising how different our statements are. It's almost as if we did a completely different task." This distinction underscores the significance of diversity in approaches to writing one's personal statement and how participants may interpret the task differently. During the peer feedback session, both Andrew and John offered valuable questions to help each other develop their statements.

The impact of the reflective exercises emerged around the idea of participants' recognizing multiple pathways for their future. When asked to reflect on how her current activities align with what she hopes to achieve, Sarah commented:

I feel like I'm pointed in the right direction, I just need make sure this is the path I want to take. (Sarah)

When Michelle was asked about how she feels about her future after graduation, she wrote:

I feel [very anxious] because I have uncertainties about my current job plans for after graduation. I also see many different paths for myself and I am not sure what is reasonable to expect, or what I should be aiming towards. (Michelle)

Sarah and Michelle, both in their final year, made reference to feelings of uncertainty about the future and being at the start of "the path" or seeing multiple paths for their next steps.

\subsection{Integrating Personal Learning with Academic Courses}

For the purposes of this research, the workshop program was framed as a professional development opportunity, independent of any required coursework. One may speculate that the lack of academic credit associated with the workshop may have negatively impacted participation. This, in turn, posed the question of how educators might integrate self-reflection on learning experiences across the span of one's formal education.

Reflective learning may look different for students depending on the academic year as they gain more exposure through diverse experiences. The importance of integration and scaffolding across the curriculum and in the classroom is emphasized by Sarah's feelings of disappointment with her current level of reflection. As a student in her final year of study, Sarah felt that she had not been encouraged to connect her personal development with her courses and felt like she had not done enough reflection up until this point in her undergraduate studies:

I feel like I haven't been getting enough out of my learning to date because I haven't been reflecting back on my learning enough throughout this whole process. (Sarah)

Self-reflection needs to be a continual and progressive exercise to avoid the potential for students to feel as if reflection has been a neglected part of their education. How can educators encourage students to think about reflection in an integrated manner? As a starting point, it may be beneficial to consider students' personal and professional development as explicit learning outcomes of engineering courses. In this way, developmental 
opportunities may be integrated within existing course structures to provide enriched learning opportunities for students.

Michelle expressed concern that, while her coursework and design courses have a strong element of "problem sets from real life", they do not provide adequate opportunities for personal development because of course constraints in exploring topics of personal interest:

Our classes and design courses do a really good job at exemplifying problem sets from real life. They fall short in personal development in that you are not given too much opportunity or slack to explore topics you are especially interested in, or even taught how to discover these topics. Anything I really enjoyed I never exactly had a hunch about before, I just stumbled in to. (Michelle)

Michelle's reflection highlights the need to consider how educators can create intentional learning opportunities for students to explore their personal interests.

In this research, we have applied self-reflection as a means for students to learn about themselves and to think about their future, however, the process of reflection can also be applied to problem solving and learning technical engineering subject matter. Therefore, the goal is for educators to consider how the integration of academic and personal development initiatives through self-reflection can support students' holistic educational experience and foster self-regulation in academic and personal contexts.

\section{CONCLUSION AND FUTURE CONSIDERATIONS}

Self-regulated learning is a multi-faceted activity. In this paper, we have focused on three themes of insight emerging from the implementation of an extra-curricular workshop program to position students for self-regulation in their personal and professional development. While the implementation of this workshop program shows potential for contributing to students' learning experiences, we highlight the need for an integrated approach to student development to ensure students have multiple exposure and diverse experiences. An understanding of students' self-reflections offers ways that educators can gain empathy to foster students' personal development in their courses.

We offer considerations for future educational research and design based on the insight gained from a preliminary qualitative analysis of the findings. Our ultimate goal is to promote a culture of self-reflection in higher education that encourages students to be self-directing agents of their educational experience. This research offers one approach to promote a culture of self-reflection as a means to foster in students the skills for self-regulated, life-long learning.

This research and program initiative adds to the growing movement to promote reflection in engineering education. Future directions for this research may be to integrate the activities into blended online course modules over an academic term with the goal of increasing access and participation. For educators who are interested in bringing self-reflection to their teaching practice, a number of questions remain to be explored. How can personal and professional learning outcomes be integrated into coursework? How might the course subject matter connect or extend to other areas of interest for each student? How do current assessment practices influence students' perspectives and behavior towards students' own interests?

This research has presented one approach to engage students in self-reflection. With a deep understanding of students' self-reflections - the characteristics, functions, and relationships - engineering educators may be better able to support students in self-regulation, in the classroom and across the curriculum.

\section{Acknowledgements}

The authors gratefully acknowledge the Natural Science and Engineering Research Council of Canada for their financial support of this research through the Chair in Design Engineering at Queen's University, Kingston, Ontario, Canada. We also gratefully acknowledge the time and dedication of the students who participated in this research.

\section{References}

[1] J. Turns, B. Sattler, K. Yasuhara, J. Borgford-Parnell, and C. Atman. "Integrating reflection into engineering education," Proc. 121st American Society for Engineering Education Annu. Conf., Indianapolis, IN, Jun. 15-18, 2014.

[2] Consortium to Promote Reflection in Engineering Education, 2014. Available: http://cpree.uw.edu/

[3] R. E. H. Wertz, S. Purzer, M. J. Fosmire, and M. E. Cardella, "Assessing information literacy skills demonstrated in an engineering design task." Journal of Engineering Education, vol. 102, no. 4, pp. 577602, 2013.

[4] C. Pomales-García, and K.C. Barreto, "Comparative analysis of student self-reflections on course projects," European Journal of Engineering Education, vol. 39, no. 6, pp. 685-699, 2014. 
[5] J.D. McNeil, Contemporary curriculum in thought and action. Hoboken, NJ: John Wiley \& Sons, 2006.

[6] R. J. Aleong, and D.S. Strong, "Exploring the self in engineering education: The design of a self-reflective workshop series to position students for selfregulation," Proc. $122^{\text {nd }}$ American Society for Engineering Education Annu. Conf., Seattle, WA, Jun. 14-17, 2015.
[7] I. Dey, Qualitative data analysis: A user-friendly guide for social scientists, New York, NY: Routledge, 1993. 